\title{
The accretion of copper and of zinc by the foetuses of prolific ewes
}

\author{
By R. B. WILLIAMS. I. MCDONALD AND I. BREMNER \\ The Rowett Research Institute, Bucksburn, Aberdeen AB2 $9 S B$
}

(Received II November 1977 - Accepted 3 February 1978)

I. The amounts of copper and zinc in the foetuses of ewes carrying from one to four lambs were measured at different stages of gestation and estimates were made of the amounts of these metals in their livers.

2. The accretion of $\mathrm{Cu}$ and $\mathrm{Zn}$ could be described by growth equations of the Gompertz form, from which could be derived estimates of the instantaneous and fractional rates of deposition of these metals in the foetal body.

3. Between the 8oth and 144th day of gestation the instantaneous rates of deposition of the metals increased exponentially, and at the end of pregnancy were calculated to be 0.24 and $2.0 \mathrm{mg} \mathrm{Cu}$ and $\mathrm{Zn} / \mathrm{d}$ respectively in the triplet lamb foetus. The corresponding total accretions were estimated to be 10 and $69 \mathrm{mg}$ respectively.

4. The fractional rates of live-weight gain and of deposition of $\mathrm{Cu}$ were similar and decreased at similar rates; that of $\mathrm{Zn}$ deposition decreased much more slowly.

5. The proportion of whole-body $\mathrm{Cu}$ estimated to be in the liver was always greater than $50 \%$. The amount of $\mathrm{Zn}$ in the liver remained constant and contributed $72 \%$ of the total body $\mathrm{Zn}$ at $80 \mathrm{~d}$ but only $8 \%$ at $144 \mathrm{~d}$.

6. The relative amounts of $\mathrm{Cu}$ and of $\mathrm{Zn}$ accrued per unit body-weight gain were not constant during the development of the foetus. As foetal numbers increased the amounts of each metal deposited in the foetus decreased more rapidly than did foetal weight.

7. The results are discussed in relation to the demands for $\mathrm{Cu}$ and $\mathrm{Zn}$ during pregnancy in sheep.

Death of the embryo or of the early postnatal animal accounts for a considerable proportion of the losses in livestock production. Deficiencies of essential trace elements in the maternal diets are known to have serious adverse effects on the development of the foetus; for example, the association of copper deficiency in sheep with the development of 'swayback' in lambs (Innes \& Shearer, 1940) is well known. Zinc deficiency states in the pregnant ruminant have not been studied, but in rats malformations of the foetus, difficult and prolonged parturition and diminished postnatal survival have occurred as a consequence of maternal Zn deprivation (Hurley \& Swenerton, 1966; Apgar, 1968; Williams, Demertzis \& Mills, 1973). The clinical signs of $\mathrm{Zn}$ deficiency are similar in animals as diverse as rats, pigs and humans (Underwood, 1977) and it may therefore be expected that in sheep, as in rats, an inadequate supply of this element during pregnancy would result in damage to the foetus or newborn lamb.

In Britain, where lambing returns show that, on average, 1.8 lambs are produced per ewe (Saunders, 1977), Cu deficiency is a recurrent, though sporadic problem. As yet, there are no unqualified reports of a deficiency of $\mathrm{Zn}$ occurring in ruminant species in this country, but the amounts occurring in natural grazings (Mills \& Dalgarno, 1972) suggest that a relatively high order of availability would be necessary to meet the demands of young rapidly growing stock. The amounts of either metal required to support pregnancy in ruminants, especially where multiple foetuses occur, can not, at present, be estimated accurately.

It is to be expected that the demands for $\mathrm{Cu}$ and $\mathrm{Zn}$ for satisfactory foetal development will be positively related to foetal numbers and, with the introduction to Britain of prolific breeds of sheep such as the Finnish-Landrace, increased demands for the trace elements, in common with other nutrients, will result. We were interested therefore to make some 
Table I. The numbers of ewes killed, grouped according to their duration of pregnancy and their foetal burden

(Total $\mathrm{Cu}$ and $\mathrm{Zn}$ were measured on all foetuses, but the concentrations of $\mathrm{Cu}$ and $\mathrm{Zn}$ in the livers were measured only in the foetuses from the numbers of ewes given in parenthesis)

\begin{tabular}{|c|c|c|c|c|c|c|c|}
\hline \multirow{2}{*}{$\begin{array}{l}\text { No. of foetuses } \\
\text { carried }\end{array}$} & \multicolumn{5}{|c|}{ Time of slaughter ( $\mathrm{d}$ from conception) } & \multirow{2}{*}{$\begin{array}{l}\text { Total } \\
\text { ewes }\end{array}$} & \multirow{2}{*}{$\begin{array}{l}\text { Total } \\
\text { foetuses }\end{array}$} \\
\hline & $80-82$ & $90-93$ & $98-$ I I 4 & I 2 I-I 37 & $139-145$ & & \\
\hline $\mathbf{I}$ & & I (I) & & I & 3 & 5 & 5 \\
\hline 2 & $2(1)$ & $I(1)$ & $3(2)$ & $3(2)$ & 3 & 12 & 24 \\
\hline 3 & I (I) & $3(3)$ & $2(2)$ & $6(2)$ & $3(\mathrm{I})$ & 15 & 45 \\
\hline 4 & & I (I) & I (I) & $2(\mathrm{I})$ & I & 5 & 20 \\
\hline Total ewes & 3 & 6 & 6 & 12 & 10 & 37 & 一 \\
\hline Total foetuses & 7 & I 6 & I 6 & 33 & 22 & - & 94 \\
\hline
\end{tabular}

assessments of the amounts of $\mathrm{Cu}$ and of $\mathrm{Zn}$ that would be accrued by multiple foetuses in the sheep. Earlier findings by Pryor (1964), Hansard \& Mohammed (1968) and Moss, Madsen, Hansard \& Gamble (1974) on the distribution of $\mathrm{Cu}$ in the foetal lamb, or on the rate of accretion of $\mathrm{Zn}$ and $\mathrm{Cu}$ during gestation, were confined almost entirely to studies on singleton lambs and at imprecisely known stages of pregnancy. We have had access to foetal material derived from the experiments of Dr J. J. Robinson of this Institute in which multiple foetuses of accurately known age were available. We were able, therefore, to make precise estimates of the rates of accretion of $\mathrm{Cu}$ and $\mathrm{Zn}$ by the foetuses and to determine whether there would be any effects of increasing foetal numbers on the $\mathrm{Cu}$ and $\mathrm{Zn}$ status of the foetal lamb. A brief report of this work has already been published (Williams \& Bremner, 1976).

\section{EXPERIMENTAL}

\section{Animals and diets}

The animals used were selected from those described by Robinson, McDonald, Fraser \& Crofts (1977); Finnish-Landrace $\times$ Polled Dorset Horn ewes were synchronized in oestrus and tupped with Suffolk rams. They were offered the diet described by Wainman, Blaxter \& Pullar (1970), which contained 43 and $8 \mathrm{mg} \mathrm{Zn}$ and $\mathrm{Cu} / \mathrm{kg}$ respectively.

We examined foetuses from thirty-seven ewes, approximately half the number of animals described by Robinson et al. (1977), and from day 80 of pregnancy only. The majority of the ewes in the experiment of Robinson et al. (1977) carried twin or triplet foetuses. This is reflected in the present sample of thirty-seven which were selected so as to include a range of litter sizes at each stage of gestation, but no exact balance was possible.

\section{Methods}

The numbers of ewes from which the foetuses were obtained, divided according to the stage of pregnancy and foetal burden, are shown in Table I, as are the numbers of ewes from which samples of foetal livers were obtained. The conditions of the experiment restricted the investigation of how the $\mathrm{Cu}$ and $\mathrm{Zn}$ were distributed in the foetuses. The weights of the livers were not measured, but the concentrations of the metals in the samples of liver were determined as described earlier (Bremner, Williams \& Young, 1977).

Each foetus was minced and freeze-dried on an aluminium tray protected by polyethylene film and the dried mince was ground to a powder which was stored in air-tight cartons. Losses of water were measured by weighing the wet or dry material at appropriate stages.

Triplicate $2 \mathrm{~g}$ samples were heated in a stainless-steel oven at $105^{\circ}$ to determine the true dry matter content of the foetus and, where necessary, corrections were made for the 
Table 2. Regression equations for the estimation of (I) total foetal contents of $\mathrm{Cu}$ and of $\mathrm{Zn}$ from age $(\mathrm{t})$, foetal weight $(\mathrm{w} ; \mathrm{kg})$ and estimated foetal weight for a triplet foetus at gestational age $\mathrm{t}\left(\mathrm{w}_{t},{ }_{3} ; \mathrm{kg}\right) ;(2)$ the concentrations of $\mathrm{Cu}$ and $\mathrm{Zn}$ in the foetal livers $\mathrm{v}$. gestational age $(\mathrm{t})$; and (3) liver weight:foetal weight $\mathrm{v}$. gestational age (1)

\section{Dependent variable}

ln (mean total $\mathrm{Cu} /$ foetus; $\mathrm{mg}$ ) $\ln$ (mean total $\mathrm{Zn} /$ foetus; $\mathrm{mg}$ )

Liver $\mathrm{Cu}$ concentration $(\mathrm{mg} / \mathrm{g})$

Liver $\mathrm{Zn}$ concentration $(\mathrm{mg} / \mathrm{g})$

Liver $w$ : foetal $w(g / k g)$

$\begin{gathered}\text { Residual } \\ \text { standard } \\ \text { deviation }\end{gathered}$
0.196
0.123
0.0081
0.021
$5 \cdot I$

amounts of dry matter (and $\mathrm{Zn}$ and $\mathrm{Cu}$ ) removed from the livers when samples had been removed for other studies. Analyses of this dried material for $\mathrm{Cu}$ and $\mathrm{Zn}$ were done after ashing at $450^{\circ}$ as described earlier for samples of rat tissue (Williams, Davies \& McDonald, 1977). Occasionally some samples contained small chips of bone so that replication of the analytical results was unsatisfactory. In these instances, two or three more samples were analysed and the mean value obtained from each foetus was used to calculate the amounts of $\mathrm{Cu}$ and $\mathrm{Zn}$ that it had contained.

\section{Statistical methods}

Because of the different stages of pregnancy at which the ewes were slaughtered and of the variability in their foetal burden, the most appropriate statistical method was the use of regression analysis to fit equations relating the measurements made to the period of time that had elapsed since conception and to the foetal load. Analyses of other data from the experiment (McDonald, Wenham \& Robinson, 1977; Robinson et al. 1977) have shown that the logarithmic form of the Gompertz growth equation,

$$
\ln y=A-B e^{-C t} \text {, }
$$

provides a sound basis for the description of measurements of foetal growth, where $y$ may be a weight or linear measurement, $t$ is the period of time (d) from conception and $A, B$ and $C$ are constants derived by least-square analyses of the data. The equation may be modified to take account of other variables by adding extra terms. In particular, the effect on any body constituent, of any deviation of a foetal weight, $w$, from the mean weight that would be expected at that time $t, w_{t}$, can be described by the equation

$$
\ln y=A-B e^{-C t}+D \ln \left(w / w_{t}\right) \text {, }
$$

where $D$ is an additional constant and $w_{t}$ is calculated from the 'triplet' version of the equation given by Robinson et al. (1977) modified so as to exclude the minor adjustment allowing for the weight of the ewe at mating (see Results).

Justification for extending these same mathematical models to the measurements of the total weights of $\mathrm{Cu}$ and of $\mathrm{Zn}$ in the individual foetuses was provided by the earlier finding (Williams et al. 1977) that the accumulation of these metals in rat foetuses was satisfactorily described by a Gompertz equation relating the weights of $\mathrm{Cu}$ and of $\mathrm{Zn}$ to the period of time that had elapsed from conception. On analysis of the present data this was again found to be so. The basic form of the relationship, equation no. 1 , could be used in the present instance but would require different values for the constants $A, B$ and $C$ according to the number of foetuses in each litter. The modified form, equation no. 2, took account of the weight of the foetuses relative to their age and a single set of values of $A, B, C$ and $D$ (Table 2) fitted all the values irrespective of litter size. 
Examination of the relationships between the concentrations of $\mathrm{Cu}$ or of $\mathrm{Zn}$ in the livers and the time of gestation showed clearly that these were non-linear in both instances. After graphical study of the measurements they were fitted empirically by exponential equations of the form

$$
y=A+B e^{C t}
$$

where $y$ is the concentration of the metal $(\mathrm{mg} / \mathrm{kg})$ in the liver, $t$ is the period of time from conception (d) and $A, B$ and $C$ are fitted constants.

Sets of measurements of liver weights $(l)$ for lamb foetuses of known ages $(t)$ and weights $(w)$ are quoted by Barcroft (1946) and Wallace (1948). They both indicate that $l: w$ decreases linearly with time, and can be combined to yield a relationship of the form

$$
l / w=A-B t,
$$

to provide estimates of liver weights for the foetuses in the present study. The combination of equations nos 3 and 4 gave estimates of the total content of $\mathrm{Cu}$ or of $\mathrm{Zn}$ in the livers.

\section{RESULTS}

The basic data consist of sets of the mean weights of $\mathrm{Cu}$ and of $\mathrm{Zn}$ per foetus for each of thirty-seven litters of lamb foetuses, together with the concentrations of $\mathrm{Cu}$ and $\mathrm{Zn}$ in the livers of the foetuses from nineteen of these litters. The values can not be condensed into tables of mean values and standard deviations in any very meaningful way, because the ewes were all killed at different times relative to conception and because of the variety of litter sizes. Instead, they must be represented almost entirely by the regression equations in Table 2 which relate the total weights of the metals in the foetus to the period of time from conception and foetal body-weight, the concentrations of the metals in the liver to gestational age alone and liver weight: foetal weight, based on earlier published values (Barcroft, I946; Wallace, I948).

The variability in the basic values was substantial, even after allowing for differences associated with gestational age and litter size, and is reflected in the residual standard deviations (RSD) given in Table 2. This must be borne in mind when making estimates from the equations. Some of our estimates are at 'one or two removes' from the values, particularly those dependent on estimates of liver weight, and must be subject to substantial error variance although this would be very difficult to quantify.

The equations in Table 2 constitute a model which incorporates the statistically significant differences that were found between foetuses from litters of different sizes in their total contents of $\mathrm{Cu}$ and $\mathrm{Zn}$. In detailing the implications of the model we shall largely confine ourselves to evaluations for triplet foetuses, for simplicity and because the mean litter size in the experiment was $2 \cdot 7$, but most of the quantitative estimates differ according to litter size. For example, the body-weight equation, $\left(\ln (w)=2 \cdot 745-17 \cdot 574 e^{-0.01976 t}-0.00079 f t\right.$ (modified from Robinson et al. (1977), see Statistical Methods) shows that at term (taken as $144 \mathrm{~d}$ from conception) the mean weight $(w ; \mathrm{kg})$ per foetus was less by a factor of $e^{(-0.00079 \times 144)}=0.89$ for each additional foetus $(f$; foetal number) carried. The equations for the total weights $(\mathrm{mg})$ of $\mathrm{Cu}$ and $\mathrm{Zn}$ imply that these would be reduced similarly by factors of $0.89^{1.39}=0.85$ and $0.89^{1.36}=0.85$ respectively. Hence, near term, a quadruplet foetus would weigh on average approximately 0.73 times as much as a singleton and contain $0.6 \mathrm{r}$ times as much $\mathrm{Cu}$ or $\mathrm{Zn}$.

The estimated total weights (mg) of $\mathrm{Cu}$ and $\mathrm{Zn}$ in a triplet foetus are graphed $v$. gestational age, in Fig. I, together with corresponding estimates of the foetal weight $(\mathrm{kg})$. 


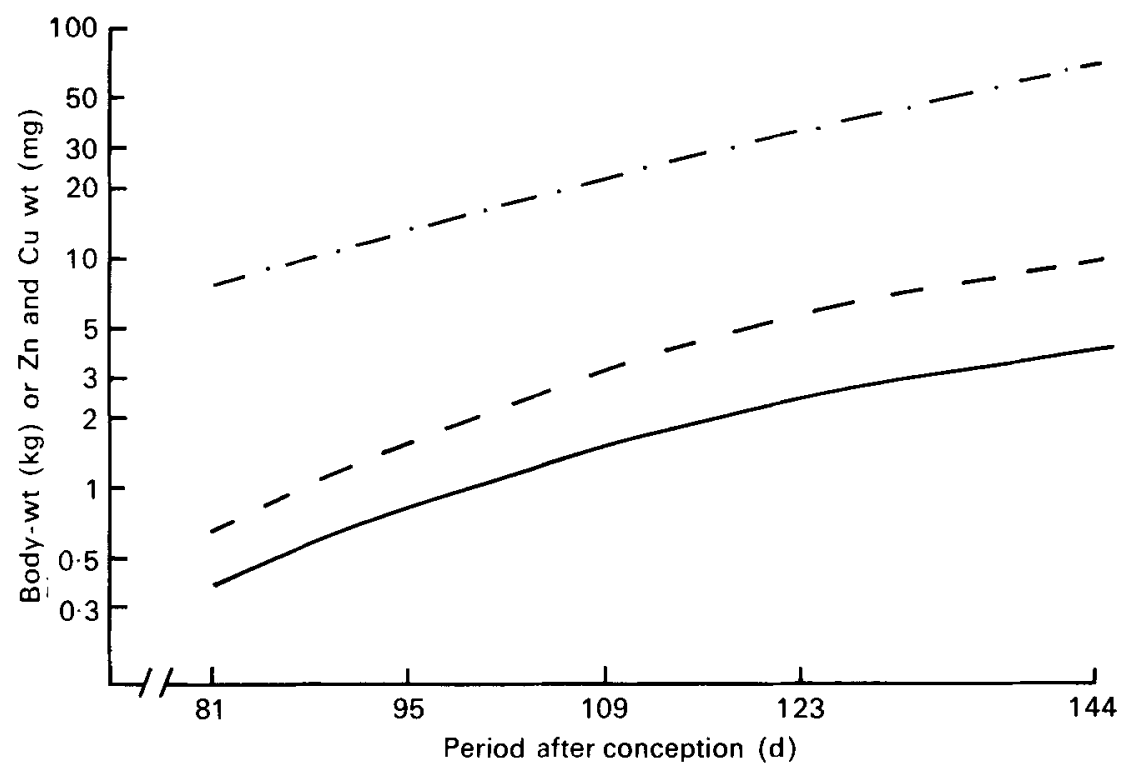

Fig. I. Semilogarithmic plots of the body-weight $(\mathrm{kg})(-)$ of, and the amounts $(\mathrm{mg})$ of $\mathrm{Cu}$ $(-$,$) and \mathrm{Zn}\left(--_{-}\right)$in the lamb foetus at the weight-for-age expected for triplets.

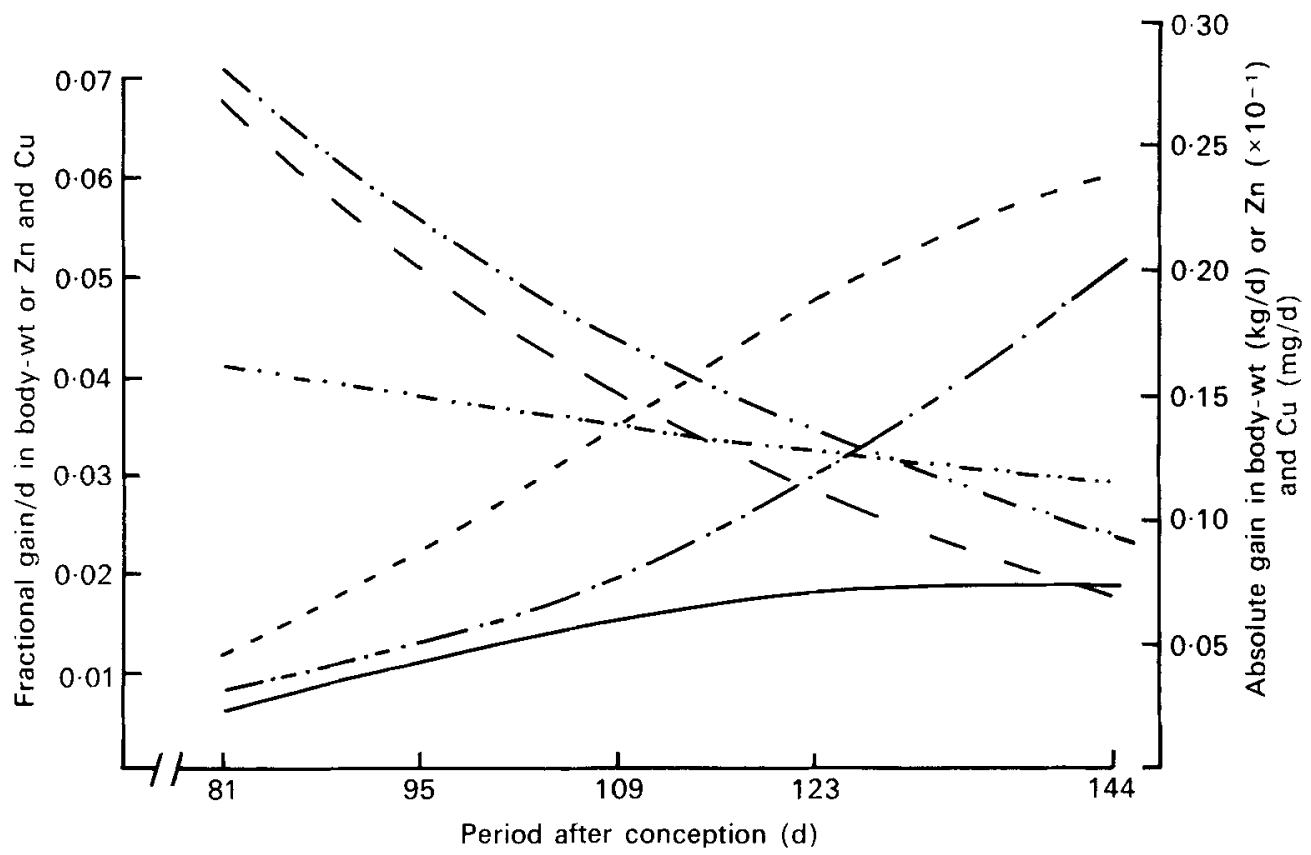

Fig. 2. The daily gains in body-weight and $\mathrm{Cu}$ and $\mathrm{Zn}$ content of the triplet lamb foetus at different stages of gestation. Absolute gain in body-wt (-) or $\mathrm{Cu}(--)$ and $\mathrm{Zn}(-\cdot-\cdot-)$. Fractional gain in body-wt (- $\rightarrow$ ) or $\mathrm{Cu}(-\cdots-)$ and $\mathrm{Zn}(-\cdots)$ ). 


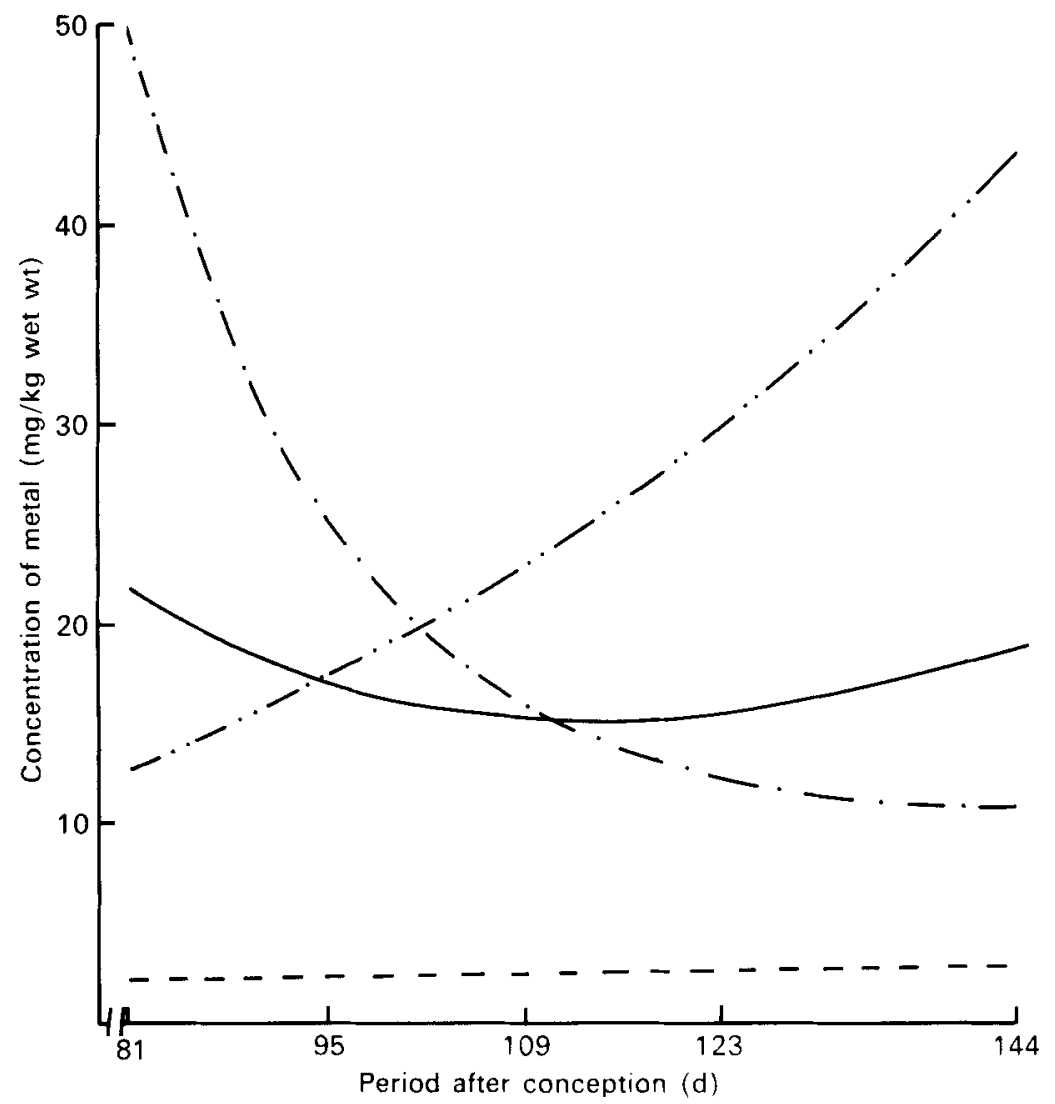

Fig. 3. The concentrations (mg/kg wet weight) of $\mathrm{Cu}(--)$ and of $\mathrm{Zn}(-)$ in the whole body and of $\mathrm{Cu}(-\cdot-)$ and $\mathrm{Zn}(\times 0.25)(-,-)$ in the liver of the lamb foetus at the weight-for-age expected for triplets.

A logarithmic scale of weight is used for convenience in covering the ranges of values and also brings out an important difference between the $\mathrm{Zn}$ curve and the others in that it shows much less curvature. This follows from the much smaller value of the decay constant, $C$, in the equation for $\mathrm{Zn}$. The slopes of the logarithmic curves measure the fractional (or specific) growth rates of the measurements and that for $\mathrm{Zn}$ decreases with gestational age more slowly than the others. The fractional growth rates can be obtained explicitly by differentiation of the logarithmic regression functions in Table 2, and estimates of the growth rates in absolute terms, the instantaneous growth rates, can then be calculated as the products with the corresponding estimated weights at any gestational age. Both the fractional and the absolute rates of gain are shown plotted against gestational age in Fig. 2 for triplet foetuses. Whereas the daily growth rate of the foetus reached a maximum of approximately $0.07 \mathrm{~kg} / \mathrm{d}$ and maintained that rate over the last 3 weeks of pregnancy, the rates at which $\mathrm{Cu}$ and $\mathrm{Zn}$ were deposited both continued to increase up to term, particularly that of $\mathrm{Zn}$ which, unlike $\mathrm{Cu}$, showed no sign of deceleration.

The fractional rates of gain of $\mathrm{Cu}$ and of body-weight are seen in Fig. 2 to be similar at all the stages of pregnancy we examined, but that of $\mathrm{Cu}$ is slightly larger throughout, consistent with a continuous increase in its concentration in the foetus over the 9-week period. The ratio of these two specific growth rates is of some theoretical interest and it 
varied relatively slightly, increasing from $\mathrm{I} \cdot 05$ at $8 \mathrm{I} \mathrm{d}$ to $\mathrm{I} \cdot 33$ at $\mathrm{I} 44 \mathrm{~d}$ of gestation. The relationship of the foetal content of $\mathrm{Cu}$ to body-weight was therefore approximately allometric and was fitted by the regression equation:

$$
\ln (\mathrm{Cu}, \mathrm{mg})=\mathrm{I} \cdot \mathrm{I} 6 \ln (w ; \mathrm{kg})+0.667 \quad(\mathrm{RSD} \pm 0 \cdot 19),
$$

in which the regression coefficient is approximately equal to the mean value of the ratios of the specific growth rates. No allometric relationship existed between the content of $\mathrm{Zn}$ and the body-weight of the foetus, in view of their very different specific growth rates, the curves of which cross over at approximately I $4 \mathrm{~d}$ of gestation (Fig. 2). Before that time the $\mathrm{Zn}$ concentration of the body was decreasing but from that age onwards it was increasing. The values for the ratios of their specific growth rates changed substantially from $0.6 \mathrm{I}$ at $8 \mathrm{I}$ d to I 63 at $\mathrm{I} 44 \mathrm{~d}$ of gestation. In absolute terms it was estimated that between I $\mathrm{I} \cdot 5$ and $13 \mathrm{mg} \mathrm{Zn}$ were accumulated per $\mathrm{kg}$ foetal-weight gain between $8 \mathrm{I}$ and $\mathrm{I} 09 \mathrm{~d}$, but thereafter this value increased to $28 \mathrm{mg} / \mathrm{kg}$ at $\mathrm{I} 44 \mathrm{~d}$. The amount of $\mathrm{Cu}$ gained per unit gain in weight increased more slowly and steadily from $1.9 \mathrm{mg} / \mathrm{kg}$ at $8 \mathrm{I} \mathrm{d}$ to $3.3 \mathrm{mg} / \mathrm{kg}$ at $\mathrm{I} 44 \mathrm{~d}$ of gestation. In consequence the amount of $\mathrm{Zn}$ relative to $\mathrm{Cu}$ that was gained decreased from 6.8 at $8 \mathrm{I} \mathrm{d}$ to 5.6 at $102 \mathrm{~d}$ and then increased again to 8.4 at $144 \mathrm{~d}$.

The curves fitted to the values for the concentrations of $\mathrm{Cu}$ and $\mathrm{Zn}$ that we found in the foetal liver samples are shown in Fig. 3 and are in sharp contrast to each other, the former increasing exponentially and the latter decreasing exponentially over the period of gestation that was covered. The corresponding whole-body concentrations calculated from the equations in Table 2 are shown for comparison. The total weights of $\mathrm{Cu}$ and $\mathrm{Zn}$ in the foetal livers may be estimated on the assumption that the weights of the livers in the foetuses we examined were in the same proportion to total foetal weights as for other lamb foetuses for which values are available. These estimates indicate that the amount of $\mathrm{Cu}$ in the liver, as a proportion of the total foetal $\mathrm{Cu}$, varied only between 0.55 and 0.63 over the last 9 weeks of gestation, possibly with a maximum value 4 weeks before term. The amount of $\mathrm{Zn}$ in the liver, on the other hand, remained virtually constant at approximately $5.6 \mathrm{mg}$ throughout the period and if expressed as a proportion of the total foetal $\mathrm{Zn}$, decreased rapidly from approximately 0.72 at $8 \mathrm{I} d$ to approximately 0.08 at $\mathrm{I} 44 \mathrm{~d}$ of gestation.

The total amounts of $\mathrm{Cu}$ and of $\mathrm{Zn}$ that were estimated to be in the body of a triplet foetus at $144 \mathrm{~d}$ were 10 and $69 \mathrm{mg}$ respectively.

\section{DISCUSSION}

The rationale for adopting the Gompertz form of equation to describe the growth of the lamb foetus and its associated structures has been discussed in detail by McDonald et al. (1977) and by Robinson et al. (1977). In the present work, it appeared that this form of equation also satisfactorily described the accretion of $\mathrm{Cu}$ and $\mathrm{Zn}$.

The observations made in this experiment confirm and extend those of Pryor (1964), Hansard \& Mohammed (1968) and Moss et al. (1974) that approximately 10 and $68 \mathrm{mg} \mathrm{Cu}$ and $\mathrm{Zn}$ respectively may be found in a lamb foetus at term and that approximately half the $\mathrm{Cu}$ is deposited in the liver. In addition, as the precise stage of pregnancy at which each ewe was slaughtered was known, the absolute rates of deposition of each metal at each stage of gestation could be estimated.

For the sake of simplicity, all values given in the text refer to the triplet lamb. The mean weight of the triplet lamb at any gestational age, $t$, may be converted to the mean weight of any other at that time by the use of the factor $e^{0.00079 t(3-f)}$, where $f$ is foetal number. The mean amounts of $\mathrm{Zn}$ and $\mathrm{Cu}$ in the singleton or other lamb at gestational age $t$ may be 
calculated from those found for the triplet lamb by the use of the factors $\left(e^{0.00079 t(3-f)}\right)^{1 \cdot 39}$ and $\left(e^{0.00079 t(3-f)}\right)^{1 \cdot 39}$ respectively. These two factors are virtually identical.

Differences in foetal numbers are reflected by differences in mean foetal weight (Robinson et al. 1977). The results of this experiment showed that the deposition of $\mathrm{Cu}$ and $\mathrm{Zn}$ in each foetus was even more affected. Effectively, therefore, the over-all concentration of each metal in the foetal body at any gestational age was diminished by an increase in foetal burden. Our calculations show that, in going from singleton to quadruplet lambs at term, the concentrations of $\mathrm{Zn}$ were $18 \cdot 8,18 \cdot 1,17.3$ and $16.6 \mathrm{mg} / \mathrm{kg}$ live-weight and those of $\mathrm{Cu}$ were $2.74,2.62,2.5 \mathrm{I}$ and 2.40 ; the ratios of $\mathrm{Zn}$ to $\mathrm{Cu}$ being virtually constant. With a fair degree of precision, therefore, it could be estimated that, if the concentration of either metal in the body is taken as an index of maturity, the triplet and quadruplet lambs were born, with respect to twins, at stages equivalent to 4 and $8 \mathrm{~d}$ prematurely. These calculations suggested that lambs derived from the larger foetal burden will, on average, be somewhat disadvantaged in terms of their $\mathrm{Cu}$ and $\mathrm{Zn}$ status but we do not know whether this would affect their chances of postnatal survival.

The total amounts of each metal gained during pregnancy by each foetus were calculated to be $80 \cdot 7,69 \cdot 1$ and $59 \cdot 2 \mathrm{mg} \mathrm{Zn}$ and $\mathrm{I} \cdot 7,10 \cdot 0$ and $8 \cdot 5 \mathrm{mg} \mathrm{Cu}$ for twins, triplets and quadruplets respectively. Since the relative amounts of each metal deposited to term remained constant, and as from five to eight times as much $\mathrm{Zn}$ as $\mathrm{Cu}$ was deposited in the developing tissue according to stage of pregnancy (the higher value at the last stages of development when demands were the greatest) it did not appear that the availability of $\mathrm{Zn}$ was a factor in restricting foetal growth in the larger litters. If this had been so, we would have expected some disproportionality in the ratio of $\mathrm{Zn}$ to $\mathrm{Cu}$ accrued.

The constancy and small amount of the hepatic $\mathrm{Zn}$ content throws doubt on earlier suggestions (Hansard \& Mohammed, 1968; Bremner, Williams \& Young, 1977) that, during development of the lamb foetus, a hepatic store of $\mathrm{Zn}$ is laid down. Hansard \& Mohammed (I968) showed that, from 95 to $140 \mathrm{~d}$ of pregnancy, the amount of $\mathrm{Zn}$ in the foetal lamb liver increased from 2.4 to $8.8 \mathrm{mg}$, compared with the almost constant value of $5.6 \mathrm{mg}$ estimated in the present study and that over the same period the total amount of $\mathrm{Zn}$ in the foetus increased from 9.0 to $68.0 \mathrm{mg}$ compared with values of 13.5 to $69.1 \mathrm{mg}$ for the triplet foetus of our experiment. In either instance, it is clear that a hepatic 'store' of $\mathrm{Zn}$ of this size would be quickly exhausted if a substantial diminution occurred in the subsequent supply of $\mathrm{Zn}$ to the foetus. In the present study, in agreement with Hansard \& Mohammed (I968), very high concentrations of $\mathrm{Zn}$ were found in the foetal liver early in gestation. A possible explanation for this high level of $\mathrm{Zn}$, which occurs to a large extent as metallothionein (Bremner et al. 1977) is that it arises as a response to the greatly increased content of $\mathrm{Zn}$ in the early foetal circulation. It is known that metallothionein synthesis in rat liver can be induced by high circulating levels of Zn (Bremner \& Davies, 1975) and Hansard \& Mohammed (I968) found that, in the $45 \mathrm{~d}$ lamb foetus, there was $7.5 \mathrm{mg} \mathrm{Zn} / \mathrm{kg}$ blood compared with amounts of 3.0 and $2.5 \mathrm{mg} / \mathrm{kg}$ at 95 and $\mathrm{I} 40 \mathrm{~d}$.

The results of our experiment suggested that from $80 \mathrm{~d}$ of pregnancy virtually all the $\mathrm{Zn}$ accrued by the foetus was deposited out with the liver. The rapidly increasing amount of $\mathrm{Zn}$ deposited per unit body-weight gain towards the end of pregnancy is probably related to its deposition into bone and wool as calcification of the former proceeds and the wool coat develops; both very necessary for the newborn lamb which is born at a relatively mature stage.

In regard to $\mathrm{Cu}$, Moss et al. (1974) calculated that between 90 and $136 \mathrm{~d}$ of pregnancy the crude rate of accretion (i.e. the average rate over the period) by all the products of conception of the ewe was I $85 \mu \mathrm{g} / \mathrm{d}$, almost exclusively by the foetus, which contained 2.84 and I $1.34 \mathrm{mg} \mathrm{Cu}$ at those times. Our values agree reasonably well, the corresponding crude 
rate of accretion for a singleton foetus was estimated, from our equation, to be $207 \mu \mathrm{g} / \mathrm{d}$. However, the estimated instantaneous rate of accretion at $136 \mathrm{~d}$ was, for a singleton foetus, $324 \mu \mathrm{g} / \mathrm{d}$, or over half as much again as the crude rate. It is clear that if effective estimates of requirements are to be accomplished, due attention must be paid to these high terminal rates.

Our finding that the concentration of $\mathrm{Cu}$ in the foetal liver increases with the duration of gestation agrees with that of McDougall (I947), whose results show mean concentrations of approximately $10 \mathrm{mg} / \mathrm{kg}$ at $88 \mathrm{~d}$ and $36 \mathrm{mg} / \mathrm{kg}$ at $144 \mathrm{~d}$ of gestation, as compared with estimates of 15 and $44 \mathrm{mg} / \mathrm{kg}$ respectively from our equation.

The results of this experiment showed that the developing lamb is totally dependent throughout gestation on an adequate supply of $\mathrm{Zn}$ from the maternal circulation. No worthwhile hepatic store existed. In terms of postnatal survival, the amount of $\mathrm{Cu}$ deposited in the liver is also very limited. From our results, it can be calculated that, in the 'non-liver' compartment at the end of pregnancy a little more than $2 \mathrm{mg} \mathrm{Cu}$ was deposited $/ \mathrm{kg}$ liveweight gain. If it is assumed that little change in this proportion occurs postnatally, then with a gain in live-weight of $150-200 \mathrm{~g} / \mathrm{d}$ the hepatic store of $\mathrm{Cu}$ would be exhausted in approximately 2 weeks in the event of a lactational deficit.

It is of interest to compare the foetal demands for $\mathrm{Cu}$ and $\mathrm{Zn}$ in late pregnancy with values for the amounts and availability of these metals in foodstuffs. Hansard \& Mohammed ( 1968 ) showed that $13 \%$ of the $\mathrm{Zn}$ in a feed containing $30 \mathrm{mg} / \mathrm{kg}$ was absorbed by pregnant ewes. Suttle \& Price (1976) estimated that the 'true availability' of $\mathrm{Cu}$ from cut herbage to non-pregnant animals was 0.048 . On the basis of these values it can be estimated that those ewes in this experiment carrying triplet foetuses and receiving between 1.75 and $2.25 \mathrm{~kg}$ of diet/d (Robinson et al. r977) would have available between 9.8 and $12.6 \mathrm{mg} \mathrm{Zn}$ or 0.67 and $0.86 \mathrm{mg} \mathrm{Cu} / \mathrm{d}$ near the end of their pregnancy. These values should be compared with our estimates of the instantaneous rates of accretion of these metals by a set of triplet foetuses which, at the end of gestation, accumulate $\mathrm{Zn}$ and $\mathrm{Cu}$ at the rate of 6.0 and $0.7 \mathrm{mg} / \mathrm{d}$. (Endogenous losses of the metals by the ewe are here disregarded.) From 25 to $35 \mathrm{mg} \mathrm{Zn} / \mathrm{kg}$ were found in samples of herbage in Britain (Mills \& Dalgarno (1972) and from 7-20 mg $\mathrm{Cu} / \mathrm{kg}$ were found by Allcroft (1952). At the lower limits of these ranges the amounts of $\mathrm{Zn}$ and $\mathrm{Cu}$ available to the ewe would be barely sufficient to support the last stages of foetal growth in a set of triplet lambs. As the rates of deposition of the metals may be as much as three times higher early in lactation it is difficult to see how these demands could be met other than by a greatly enhanced absorption of these metals (as occurs in the instance of $\mathrm{Zn}$ in pregnant and lactating rats (Davies \& Williams, 1977)) or else by severe demands on the body of the ewe.

Our findings that there are substantial changes in the relative demands for trace metals during foetal development in sheep, as in rats (Williams et al. 1977), indicate that it would be difficult to formulate precise estimates of requirements throughout pregnancy but that knowledge of the maximum demands that may arise is of primary importance.

The authors are grateful to Dr J. J. Robinson for allowing them access to his experimental material and thank Mr S. J. Miller for his assistance with the trace metal analyses.

\section{REFERENCES}

Allcroft, R. (1952). Vet Rec. 64, 17.

Apgar, J. (1968). Am. J. Physiol. 215, I60.

Barcroft, J. (1946). Researches on Pre-Natal Life, vol. I. Oxford: Blackwell.

Bremner, I. \& Davies, N. T. (1975). Biochem. J. 149, 733.

Bremner, I., Williams, R. B. \& Young, B. W. (1977). Br. J. Nutr. 38, 87. 
Davies, N. T. \& Williams, R. B. (1977). Br. J. Nutr. 38, 417.

Hansard, S. L. \& Mohammed, A. S. (I968). J. Anim. Sci. 27, 807.

Hurley, L. S. \& Swenerton, H. (1966). Proc. Soc. exp. Biol. Med. 123, 692.

Innes, J. R. M. \& Shearer, G. D. (I940). J. comp. Pathol. 53, I.

McDonald, I., Wenham, G. \& Robinson, J. J. (1977). J. agric. Sci., Camb. 89, 373.

McDougall, E. I. (1947). J. agric. Sci., Camb. 37, 337.

Mills, C. F. \& Dalgarno, A. C. (1972). Nature, Lond. 239, I7I.

Moss, B. R., Madsen, F., Hansard, S. L. \& Gamble, C. T. (1974). J. Anim. Sci. 38, 475.

Pryor, W. J. (1964). Res vet. Sci. 5, I 23.

Robinson, J. J., McDonald, I., Fraser, C. \& Crofts, R. M. J. (1977). J. agric. Sci., Camb. 88, 539.

Saunders, R. W. (1977). Biochem. Soc. Trans. 5, 447.

Suttle, N. \& Price, J. (1976). Anim. Proc. 23, 233.

Underwood, E. J. (1977). Trace Elements in Human and Animal Nutrition, $4^{\text {th }}$ ed. New York and London: Academic Press.

Wainman, F. W., Blaxter, K. L. \& Pullar, J. D. (1970). J. agric. Sci., Camb. 74, 3 I I.

Wallace, L. R. (1948). J. agric. Sci., Camb. 38, 243.

Williams, R. B. \& Bremner, I. (1976). Proc. Nutr. Soc. 35, 86A.

Williams, R. B., Davies, N. T. \& McDonald, I. (1977). Br. J. Nutr. 38, 407.

Williams, R. B., Demertzis, P. \& Mills, C. F. (1973). Proc. Nutr. Soc. 32, 3A. 